\title{
Maternal Near Miss and quality of care in a rural Rwandan hospital
}

Richard Kalisa ${ }^{1,2^{*}}$, Stephen Rulisa ${ }^{3}$, Thomas van den Akker $^{4}$ and Jos van Roosmalen ${ }^{2,4}$

\begin{abstract}
Background: The WHO Maternal Near Miss (MNM) approach was developed to evaluate and improve quality of obstetric care worldwide. This study aimed to study the incidence of MNM and quality of care at a district hospital in rural Rwanda by applying this approach.

Methods: A facility based, prospective cohort study conducted at a district hospital in rural Rwanda between June 2013 and December 2014. Subjects were followed from time of admission to discharge or death.

Results: In 3979 deliveries, 3827 singletons and 152 twins pairs were born. Among the 4131 neonates, there were 3994 live births and 137 stillbirths. Ninety-nine women suffered severe maternal outcome (SMO): 86 maternal near misses and 13 deaths. This adds up to a maternal near miss ratio of 21.5 per 1000 live births (95\% Cl 17.3-26.5), a maternal mortality ratio of 325 per 100000 live births $(95 \% \mathrm{Cl} 181-543)$ and a mortality index of $13.1 \%(95 \% \mathrm{Cl}$ 7.3-21.9). Hemorrhage $(n=49,57 \%)$ and hypertensive disorders $(n=27,31.4 \%)$ were the commonest MNM conditions. Eclampsia ( $n=4 / 13 ; 30.7 \%$ ) was the leading cause of maternal mortality, while sepsis/peritonitis following cesarean section $(n=2 / 6 ; 33.3 \%)$ had the highest mortality index. Seventy-seven out of 99 SMO cases $(77.9 \%)$ were referred from other facilities with critical conditions and 28 out of 99 SMO cases (28.3 \%) were admitted into the Intensive Care Unit. Several indicators such as administration of oxytocin, magnesium sulfate and antibiotics were found to be suboptimal.
\end{abstract}

Conclusions: MNM is common at district level in Rwanda. The MNM approach enabled us to identify shortfalls in clinical practice and the referral system.

Keywords: Audit, Maternal morbidity, Maternal mortality, Maternal near miss, Obstetrics, Quality of care

\section{Background}

Most maternal deaths occur during the intrapartum and immediate postpartum period from preventable or treatable causes such as hemorrhage, eclampsia and sepsis [1]. The majority of these women die in low-income countries, and several countries in sub-Saharan Africa have very high maternal mortality ratios (MMR), often double the estimated global MMR of 400 per 100,000 live births [2].

Although global and regional population based numbers of maternal deaths remain high, numbers at the facility level are relatively low. It has been shown that reviewing critical incidents, including obstetric audits

\footnotetext{
* Correspondence: kalichard@gmail.com

${ }^{1}$ Department of Obstetrics and Gynecology, Ruhengeri Hospital, Musanze, Rwanda

${ }^{2}$ Athena Institute, VU University, Amsterdam, The Netherlands

Full list of author information is available at the end of the article
}

at facility level, may improve quality of facility based care [3] and functioning of the broader health system [4-6].

Until recently, a variety of criteria was used to define severe maternal morbidity or maternal near miss (MNM) [4]. In 2011, the World Health Organization (WHO) developed a systematic MNM approach. The aim was to facilitate comparisons between different studies, and between countries and regions [7], in order to address shortcomings in quality of obstetric care and improve pregnancy outcome [8]. Within this approach, an MNM refers to 'a woman who almost died but survived a complication during pregnancy, childbirth, or within 42 days after termination of pregnancy' $[9,10]$, and organ failure based criteria reflect critical illness and allow for identification of MNM. A number of studies 
have applied these criteria in low-income countries $[8,11-14]$.

In Rwanda, the MMR has been reduced by roughly two-thirds from 750 in 2005 to 210 per 100000 live births in 2015 [15, 16]. This may have resulted from strong government commitment combined with a well-organized community based health program, performance based financing, innovative community health insurance, and SMS-based alert systems among other policy changes [17, 18]. Nevertheless, additional progress is needed, and evaluation of MNM may be of increasing use in light of this mortality reduction. This study aimed to assess MNM characteristics and process indicators related to quality of care at a district hospital in rural Rwanda, by applying the WHO MNM approach.

\section{Methods}

This was a prospective cohort study among pregnant women who were admitted for delivery or pregnancy related complications, and who sustained severe acute maternal morbidity at Ruhengeri maternity ward in Musanze district, Rwanda, between June 2013 and December 2014. Musanze is located in northern Rwanda, at $94 \mathrm{~km}$ from the capital Kigali, and has a population of 368267 inhabitants with a total fertility rate of 4.6 births per woman [16].

Ruhengeri hospital acts as a provincial referral hospital for high-risk obstetric cases from health centers and other district hospitals in the northern province. Annually, 3500 deliveries are conducted at the facility. During the study period, medical staff consisted of one specialist obstetrician, four medical officers, two intern doctors and 18 midwives. Patients with critical conditions were admitted into the intensive care unit (ICU), where vital signs were monitored hourly, and treatment with vasoactive drugs and mechanical ventilation could be provided. Blood for transfusion was supplied by the regional blood bank located next to the hospital.

Eligibility for the study was not restricted by gestational age. Therefore, women who had had an abortion or ectopic pregnancy and met the WHO MNM criteria were also included [7, 10]. Women who developed complications more than 42 days after termination of pregnancy were not eligible. On a daily basis, we captured relevant data for every woman who presented with severe acute maternal morbidity or died during admission, by using available medical records. Severe Maternal Outcome (SMO) was defined as MNMs and maternal deaths combined.

Two trained research assistants screened possible participants and the principal investigator (RK) verified suitability for study inclusion. Possible participants included patients who had severe maternal complications at baseline, received critical interventions or were admitted into the ICU, according to WHO guidelines
[10]. We tried as much as possible to apply the WHO MNM criteria but had to make several modifications due to lack of laboratory tests and management options (Table 1). For every case, information was collected regarding socio-demographic characteristics, gestational age, maternal and neonatal outcome, as well as process indicators regarding prevention and treatment of the main causes of MNM and death: giving magnesium sulfate for treatment of eclampsia, oxytocin for prevention and treatment of postpartum hemorrhage, and antibiotics for prophylaxis (during cesarean section) and treatment of sepsis.

Data were entered into Microsoft Excel, and subsequently entered into STATA version 12 for analysis. Outcomes were given in proportions with $95 \%$ confidence intervals (CIs). The results are presented in accordance with the WHO MNM approach.

\section{Results}

During the 19-month study period, there were 3979 deliveries, in which 3827 singletons and 152 twins pairs were born. Among the 4131 neonates, there were 3994 live births, and 137 stillbirths. Three hundred thirty two women sustained potentially life-threatening conditions and 99 had SMO: 86 near misses and 13 maternal deaths. The cesarean section rate for Ruhengeri hospital was $34.9 \%$.

Cases of morbidity were classified by underlying causes and type of organ system dysfunction (Tables 2 and 3). The commonest conditions contributing to MNM were severe hemorrhage $(n=49 ; 57 \%)$, but with MI 5.8 \% (95 \% CI 1.5-15.7). Severe hypertensive disorders was the second main cause of morbidity $(n=$ 27; 31.4 \%) with MI $13 \%$ (95 \% CI 4.1-31.1). Eclampsia $(n=4 / 13 ; 30.7 \%)$ was the leading cause of maternal mortality, while sepsis/peritonitis following cesarean section $(n=2 / 6 ; 33.3 \%)$ had the highest mortality index. Other common contributing factors among MNM cases were lack of health insurance $(n=23$; $26.7 \%)$, anemia $(n=21 ; 24.4 \%)$ and previous cesarean section $(n=12 ; 14 \%)$.

Most common organ dysfunctions among women with MNM conditions were cardiovascular dysfunction $(n=56 ; 65.1 \%)$ followed by multiple organ dysfunction $(n=35 ; 40.7 \%)$. The mortality index was highest for hepatic dysfunction, (33.3\%). The MNM/mortality ratio was highest for cardiovascular dysfunction (8:1), followed by renal and neurologic dysfunction (5:1) (Table 3).

Cesarean section was performed in many women with potentially life threatening conditions $(n=125 / 332$; $37.7 \%)$, MNM ( $n=37 / 86 ; 43 \%)$ and maternal deaths $(n=3 / 13 ; 23.1 \%)$. Neonatal outcomes (preterm births, 
Table 1 WHO near miss criteria and modifications for Ruhengeri hospital

\begin{tabular}{|c|c|}
\hline WHO near miss criteria [10] & $\begin{array}{l}\text { Ruhengeri near } \\
\text { miss criteria }\end{array}$ \\
\hline \multicolumn{2}{|l|}{ Clinical Criteria } \\
\hline Acute Cyanosis & Not modified \\
\hline Gasping & Not modified \\
\hline Respiratory rate $>40$ or $<6 / \mathrm{min}$ & Not modified \\
\hline Shock $k^{\mathrm{a}}$ & Not modified \\
\hline Oliguria non responsive to fluids or diuretics ${ }^{b}$ & Not modified \\
\hline Failure to form clots $^{c}$ & Not modified \\
\hline Loss of consciousness lasting $>12 \mathrm{~h}^{\mathrm{d}}$ & Not modified \\
\hline 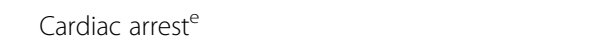 & Not modified \\
\hline Stroke ${ }^{f}$ & Not modified \\
\hline Uncontrollable fit/total paralysis ${ }^{9}$ & Not modified \\
\hline Jaundice in the presence of pre-eclampsiah & Not modified ${ }^{i}$ \\
\hline \multicolumn{2}{|l|}{ Laboratory-based criteria } \\
\hline Oxygen saturation $<90 \%$ for $\geq 60 \mathrm{~min}$ & Not modified \\
\hline $\mathrm{PaO} 2 / \mathrm{FiO} 2,200$ mmHg & Not available $e^{j}$ \\
\hline Creatinine $\geq 300 \mathrm{mmol} / \mathrm{l}$ or $\geq 3.5 \mathrm{mg} / \mathrm{dL}$ & Not modified \\
\hline Bilirubin > $100 \mathrm{mmol} / \mathrm{l}$ or $.6 .0 \mathrm{mg} / \mathrm{dL}$ & Not modified \\
\hline $\mathrm{pH}<7.1$ & Not available \\
\hline Lactate $>5 \mathrm{mEq} / \mathrm{mL}$ & Not available \\
\hline Acute thrombocytopenia ( $<50,000$ platelets/ml) & Not modified \\
\hline ketoacids in urine & Not available \\
\hline \multicolumn{2}{|l|}{ Management-based criteria } \\
\hline Admission to intensive care unit & Not modified \\
\hline Use of continuous vasoactive drugs & Not modified \\
\hline Hysterectomy following infection or hemorrhage & Not modified \\
\hline Transfusion of $\geq 5$ units of blood & Not modified \\
\hline $\begin{array}{l}\text { Intubation and ventilation for } \geq 60 \mathrm{~min} \text { not } \\
\text { related to anesthesia }\end{array}$ & Not modified \\
\hline Dialysis for acute renal failure & Not available \\
\hline Cardio-pulmonary resuscitation & Not modified \\
\hline
\end{tabular}

Table 1 WHO near miss criteria and modifications for Ruhengeri hospital (Continued)

Severe maternal complication

\section{Eclampsiak $^{k}$}

Sepsis or severe systemic infection

Ruptured uterus ${ }^{m}$

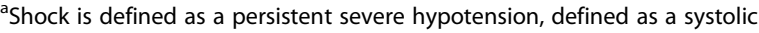
blood pressure $<90 \mathrm{mmHg}$ for $60 \mathrm{~min}$ with a pulse rate of $\geq 120 / \mathrm{min}$ despite aggressive fluid replacement $(>2 \mathrm{~L}$ )

boliguria is defined as an urinary output $<30 \mathrm{ml} / \mathrm{h}$ for $4 \mathrm{~h}$ or $<400 \mathrm{ml} / 24 \mathrm{~h}$ ${ }^{C}$ Failure to form clots is defined as the absence of clotting from the IV site after 7-10 min

${ }^{\mathrm{d}}$ Unconsciousness/coma lasting $>12 \mathrm{~h}$ is defined as a profound alteration of mental state that involves complete or near-complete lack of responsiveness to external stimuli or Glasgow Coma Scale $<10$

${ }^{e}$ Cardiac arrest is defined as loss of consciousness and absence of pulse or heart beat fStroke is defined as a neurological deficit of cerebrovascular cause that persists $\geq 24 \mathrm{~h}$, or is interrupted by death within $24 \mathrm{~h}$

gUncontrollable fit is a condition in which the brain is in state of continuous seizure

${ }^{h}$ Pre-eclampsia: the presence of hypertension associated with proteinuria. Hypertension is defined as a blood pressure $\geq 140 \mathrm{mmHg}$ (systolic) or $\geq 90 \mathrm{mmHg}$ (diastolic). Proteinuria is defined as excretion of $\geq 300 \mathrm{mg}$ protein/24 h or $300 \mathrm{mg}$ protein/l urine or $\geq 1+$ on a dipstick

'Was not regularly available due to lack of resources

jNot available

${ }^{\mathrm{k}}$ Eclampsia is defined as the presence of hypertension associated with proteinuria and fits

'Sepsis is defined as a clinical sign of infection and 3 of the following: temp $>38$ Cor $<36$, respiration rate $>20 / \mathrm{min}$, pulse rate $>90 / \mathrm{min}, \mathrm{WBC}>12$, clinical signs of peritonitis

mUterine rupture is defined as the complete rupture of a uterus during labor

stillbirths and perinatal deaths) were worst among maternal deaths and comparable between women with potentially life threatening conditions and maternal near misses (Table 4).

The SMO ratio was 24.8 per 1000 live births $(95 \%$ CI 20.3-30.1), and the MNM ratio 21.5 per 1000 live births (95 \% CI 17.3-26.5). The maternal mortality ratio (MMR) was 325 (95\% CI 181-543) per 100000 live births, the mortality index $(\mathrm{MI}=$ maternal deaths $/ \mathrm{MNM}$ + maternal deaths) $13.1 \%$ (95\% CI 7.3-21.9), and the maternal near miss mortality ratio (MNM: maternal deaths) 7:1 (Table 5). In 332 women, 234 critical interventions were carried out, including 108 blood transfusions (32.5 \% of women) and 71 laparotomies (21.4 \% of women). The ICU admission rate was $1.4 \%(61 / 4353)$ among all women, whereas ICU admission rate among women with SMO was $28.3 \%$ (28/99) and proportion of maternal deaths occurred without ICU admission was $46 \%(6 / 13)$ (Table 5). Of 134 women with severe hemorrhage, $52(38,8 \%)$ were transfused five or more units of blood.

Among women with SMO, oxytocin was given in 3862 women (93.5 \%) for prevention of postpartum hemorrhage, and only 97 of 134 women with severe $\mathrm{PPH}(72.4 \%)$ received oxytocin as treatment. Almost all women with eclampsia (52/53; $98.1 \%)$ received magnesium sulphate. Intra-operative prophylactic antibiotics were 
Table 2 Underlying causes and contributory factors of potentially life-threatening conditions (PLTC) and severe maternal outcomes ${ }^{\mathrm{a}}$

\begin{tabular}{|c|c|c|c|c|c|}
\hline & $\begin{array}{l}\text { Women with PLTC } \\
332(\%)\end{array}$ & $\begin{array}{l}\text { MNM } \\
86(\%)\end{array}$ & $\begin{array}{l}\text { Maternal deaths } \\
13(\%)\end{array}$ & MNMR/1000 live birth & $\begin{array}{l}\text { Mortality index } \\
\text { (\%) }\end{array}$ \\
\hline \multicolumn{6}{|l|}{ Underlying causes ${ }^{\mathrm{b}}$} \\
\hline Severe hemorrhage & $134(40.4)$ & $49(57)$ & $3(23.1)$ & $12.3(9.2-16.1)$ & $5.8(1.5-15.7)$ \\
\hline Abortion & $33(9.9)$ & $7(8.1)$ & $0(0)$ & & \\
\hline Ectopic & $21(6.3)$ & $13(15.2)$ & $0(0)$ & & \\
\hline Molar & $4(1.2)$ & $0(0)$ & $0(0)$ & & \\
\hline Placental abruption & $10(3.0)$ & $4(4.6)$ & $0(0)$ & & \\
\hline Placenta Previa & $17(5.1)$ & $6(7.0)$ & $0(0)$ & & \\
\hline Postpartum Hemorrhage & $49(14.8)$ & $19(22.1)$ & $3(23.1)$ & & \\
\hline Hypertensive disorders & $93(28.0)$ & $27(31.4)$ & $4(30.7)$ & $6.8(4.6-9.7)$ & $13(4.1-31.1)$ \\
\hline Severe Pre-eclampsia & $40(43.0)$ & $7(8.1)$ & $0(0)$ & - & \\
\hline Eclampsia & $53(57.0)$ & $20(23.3)$ & $4(30.7)$ & & \\
\hline Pregnancy related infections ${ }^{c}$ & $40(12.1)$ & $0(0)$ & $2(15.4)$ & - & \\
\hline Sepsis/peritonitis post-cesarean & $38(11.4)$ & $4(4.7)$ & $2(15.4)$ & $1.0(0.3-2.4)$ & $33.3(5.6-110.1)$ \\
\hline Unanticipated complications of management ${ }^{d}$ & $0(0)$ & $2(2.3)$ & $1(7.7)$ & $0.5(0.1-1.7)$ & $14.3(1.6-164.4)$ \\
\hline Coincidental conditions $^{e}$ & $2(0.6)$ & $0(0)$ & $0(0.0)$ & - & \\
\hline Unknown & $0(0)$ & $0(0)$ & $1(7.7)$ & - & \\
\hline Other obstetric complications $^{f}$ & $16(4.8)$ & $4(4.7)$ & & - & \\
\hline \multicolumn{6}{|l|}{ Associated conditions } \\
\hline Anemia & $73(22)$ & $21(24.4)$ & $4(30.8)$ & $5.3(3.3-7.9)$ & $16.0(5.1-38.6)$ \\
\hline HIV & $16(4.8)$ & $8(9.3)$ & $2(15.4)$ & $2.0(0.9-3.8)$ & $20.0(3.3-66.1)$ \\
\hline Previous CS & $22(6.6)$ & $12(14)$ & $1(7.7)$ & $3.0(1.6-5.1)$ & $7.7(0.3-37.9)$ \\
\hline Prolonged/obstructed Labor & $5(1.5)$ & $5(5.8)$ & $1(7.7)$ & $1.3(0.5-2.8)$ & $16.7(0.8-82.2)$ \\
\hline Lack of medical Insurance & $28(8.4)$ & $23(26.7)$ & $4(30.8)$ & $5.8(3.7-8.5)$ & $14.8(4.7-35.7)$ \\
\hline
\end{tabular}

${ }^{a}$ Values given as number (percentages)

${ }^{b}$ One woman could have experienced more than one cause

'Pyelonephritis (12 PLTC), Hyperemesis (10 PLTC), Choriamnionitis (8 PLTC), Endometritis (8 PLTC), severe malaria (2 PLTC, 1 MD), HIV encephalopathy (1 MD)

datrogenic complications (2 MNM, 1 MD)

e Road traffic accident, Stevens-Johnson syndrome (2 PLTC)

${ }^{\mathrm{f} A s t h m a t i c ~ c r i s i s ~(6 ~ P L T C), ~ H e r b a l ~ i n t o x i c a t i o n ~(4 ~ P L T C), ~ E p i l e p s y ~(3 ~ P L T C, ~} 1$ MNM), Unknown cause of Jaundice (2 PLTC), Blood transfusion reaction (1 PLTC, 1MNM),

Peripartum cardiomyopathy (2 MNM)

Table 3 Frequencies of maternal near miss and maternal death by type of organ system dysfunction

\begin{tabular}{lllll}
\hline Organ dysfunctions & MNM cases $n=86(\%)$ & Maternal death $n=13(\%)$ & MNM mortality ratio & Mortality index (\%) $95 \%$ Cl \\
\hline Cardiovascular & $56(65.1)$ & $7(53.8)$ & $8: 1$ & $11.1(4.9-21)$. \\
Renal & $5(5.8)$ & $1(7.7)$ & $5: 1$ & $16.7(0.8-82.2)$ \\
Respiratory & $25(29.1)$ & $6(46.2)$ & $4: 1$ & $19.4(7.9-40.3)$ \\
Hepatic & $6(7.0)$ & $5(23.1)$ & $2: 1$ & $33.3(8.5-90.7)$ \\
Neurologic & $26(30.2)$ & $7(53.8)$ & $5: 1$ & $16.1(5.9-35.8)$ \\
Hematologic & $16(18.6)$ & $3(23.1)$ & $2: 1$ & $30.4(13.3-60.2)$ \\
Hysterectomy/Uterine & $8(9.3)$ & $9(69.2)$ & $3: 1$ & $27.3(6.9-74.2)$ \\
Multiple organ & $35(40.7)$ & $2(15.4)$ & $4: 1$ & $20.5(9.9-37.5)$ \\
Unspecified organ & - & & - \\
\hline
\end{tabular}


Table 4 End of pregnancy and birth outcomes in our study population

\begin{tabular}{|c|c|c|c|c|c|}
\hline & $\begin{array}{l}\text { No severe } \\
\text { complication (\%) }\end{array}$ & $\begin{array}{l}\text { Potentially life-threatening } \\
\text { conditions (\%) }\end{array}$ & $\begin{array}{l}\text { Maternal near } \\
\text { miss cases (\%) }\end{array}$ & $\begin{array}{l}\text { Maternal deaths } \\
(\%)\end{array}$ & All women \\
\hline & 3922 & 332 & 86 & 13 & 4353 \\
\hline \multicolumn{6}{|l|}{ End of pregnancy } \\
\hline Vaginal Delivery & $2344(59.8)$ & $113(34.1)$ & $18(20.9)$ & $7(53.8)$ & $2482(57.1)$ \\
\hline Vacuum Extraction & $156(3.9)$ & $37(11.1)$ & $0(0.0)$ & $0(0.0)$ & $193(4.4)$ \\
\hline Cesarean section & $1277(32.6)$ & $125(37.7)$ & $37(43)$ & $3(23.1)$ & $1442(33.1)$ \\
\hline Complete abortion, vacuum aspiration/curettage & $94(2.4)$ & $33(9.9)$ & $7(8.1)$ & $0(0.0)$ & $134(3.1)$ \\
\hline Laparotomy for ruptured uterus & $0(0.0)$ & $3(0.9)$ & $11(12.8)$ & $1(7.7)$ & $15(0.3)$ \\
\hline Women discharged or died still pregnant & $17(0.4)$ & $0(0.0)$ & $0(0.0)$ & $2(15.4)$ & $19(0.4)$ \\
\hline Laparotomy for ectopic pregnancy & $34(0.9)$ & $21(6.3)$ & $13(15.2)$ & $0(0.0)$ & $68(1.6)$ \\
\hline Cesarean section rate ${ }^{a}$ & n/a (33.8) & n/a (45) & n/a (56.1) & n/a (27.3) & n/a (34.9) \\
\hline Preterm Birth & $268(7.1)$ & $32(11.5)$ & $5(7.6)$ & $2(18.1)$ & 307 (7.4) \\
\hline Fresh Stillbirth & $46(1.2)$ & $5(1.8)$ & $6(9.1)$ & $3(27.3)$ & $60(1.5)$ \\
\hline Macerated Stillbirth & $76(2.0)$ & $0(0.0)$ & $0(0.0)$ & $1(9.1)$ & $77(1.9)$ \\
\hline Perinatal death ${ }^{b}$ & $107(2.83)$ & $17(6.1)$ & $6(9.1)$ & $5(45.5)$ & $130(3.1)$ \\
\hline
\end{tabular}

${ }^{a}$ Cesarean deliveries divided by all deliveries $/{ }^{b}$ Fetal deaths + intra hospital early neonatal mortality

administered to 1409 out of 1442 women (97.7 \%) who delivered by cesarean section. Only 18 of 38 women (47.4\%) with sepsis received parenteral antibiotics (Table 6).

\section{Discussion}

This is the first study of SMO at a district hospital in rural Rwanda. The high prevalence of MNM in our study lies within the wide range of ratios reported in studies from other low-income countries, which used similar near miss criteria $[11,19,20]$. The high MNMR of 21.5 per 1000 live births in our study may be explained by: i) different interpretations of the criteria [12-14], ii) delayed referral of SMO cases $(77.9 \%$ compared to $20.9-64.4 \%$ in the other studies) or iii) the high proportion of women without medical insurance which may have led to delay in seeking or providing care. The higher mortality index for MNM of $13.1 \%$ in our and similar studies from Africa $[8,13,14]$ compared to middle-income countries [5], demonstrates that a larger number of critically ill women in low-resource settings die from such severe complications.

The main direct causes of SMO were obstetric hemorrhage and hypertensive disorders, comparable to other studies in low-resource countries [11-14]. Mortality indices for these conditions were lower than in other studies, probably due to wide availability of blood for transfusion and magnesium sulfate in our setting. Particular attention is needed for conditions with a high mortality index, in particular post-cesarean sepsis and peritonitis, which were previously reported to also be a problem at a tertiary hospital in Rwanda [14]. The relative inexperience from medical officers working in district hospitals (generally recent medical school graduates) may compound this problem [21], combined with improper use of antibiotics and poor sterilization procedures [22]. These findings are extremely worrying in light of the very high cesarean section rate. This rate calls for rigorous audit of cesarean section indications [23].

Two-thirds of SMO cases were received in critical condition from other facilities or home. This may indicate difficulties in the referral system or detection of pregnant women with life threatening complications outside health facilities due to delays in seeking or reaching care [19]. Women who were referred constituted the large majority of all women with SMO. It also addresses quality of care in lower-level health facilities. When analyzing access to care, it is essential to separate near miss cases on arrival from those developing in the hospital. This would be unexpectedly high given the government's commitment towards improving maternal and neonatal health care through use of its existing programs $[17,18]$ to reduce first and second delays [24]. This highlights a number of potential interventions, such as educating pregnant women and their caretakers on obstetric danger signs [21] and training health care workers at lower level facilities in emergency obstetric care [25].

MNM developed in one quarter of women with potentially life threatening conditions, with high MNMRs due to cardiovascular, renal and neurologic dysfunction. Suboptimal use of some evidence-based practices explains these SMO cases. The use of uterotonic drugs to prevent $\mathrm{PPH}$ was high; however, less than three out of four women who developed $\mathrm{PPH}$ received oxytocin as a treatment. Similarly, use of prophylactic antibiotics for cesarean delivery was high; however, less than half of 
Table 5 Severe maternal outcomes, near miss indicators and facility-related indicators, including $95 \%$ confidence intervals

\begin{tabular}{ll}
\hline Maternal outcomes and indicators $^{\text {a }}$ & Value \\
\hline Severe maternal outcomes (SMO) cases $(n)$ & 99 \\
Cases of maternal death $(n)$ & 13 \\
Cases of maternal near miss $(n)$ & 86
\end{tabular}

Overall near miss indicators

'Severe maternal outcome ratio (per 1000 live births)

$24.8(20.3-30.1)^{b}$

Maternal near miss incidence ratio

(per 1000 live births)

${ }^{\mathrm{d}}$ Maternal near miss mortality ratio

"Mortality index

$21.5(17.3-26.5)^{\mathrm{b}}$

$7: 1$

$13.1 \%(7.3-21.9)$

Hospital access indicators ${ }^{b}$

SMO cases presenting with organ dysfunction

or maternal death within $12 \mathrm{~h}$ of

hospital stay (SM012) (n)

Percentage of SM012 cases among all SMO cases

Percentage of SM012 cases coming from other health facilities

SM012 mortality index

$79.8(63.6-98.9)$

$79.8(63.6-98.9)$

$77.8(61.8-96.7)$

$8.1(3.6-16.1)$

Intra-hospital care

Intra-hospital SMO cases of organ dysfunction or maternal death after $12 \mathrm{~h}$ of hospital stay

Rate of intra-hospital SMO (per 1000 live births)

Intra-hospital mortality index

$8.0(5.6-11.2)$

$15.8(6.4-32.8)$

Intensive care used ${ }^{a}$

Percentage of ICU admission

$1.4(1.1-1.8)$

Percentage of ICU admission among

$28.3(19.2-40.3)$

women with SMO

Percentage of SMO among women admitted to ICU

$73.8(54.5-97.8)$

Percentage of maternal deaths occurred without ICU admission
Table 6 Use of interventions for prevention and treatment of major obstetric complications

\begin{tabular}{ll}
\hline Interventions & $n(\%)$ \\
\hline Prevention of PPH & \\
$\begin{array}{l}\text { Target population: women giving birth in health } \\
\text { facilities }\end{array}$ & 4131 \\
Oxytocin & $3862(93.5 \%)$
\end{tabular}

Treatment of severe PPH

Target population: women with severe PPH

Oxytocin

$97(72.4 \%)$

Ergometrine

$105(78.4 \%)$

Misoprostol

$44(32.8 \%)$

Other uterotonics

$62(46.3 \%)$

Removal of retained products

$18(13.4 \%)$

Artery ligation

$7(5.2 \%)$

Hysterectomy

$4(2.9 \%)$

$8(5.9 \%)$

Abdominal packing

$52(38.8 \%)$

Cases with SMO

$3(2.2 \%)$

Anticonvulsants for Eclampsia

Target population: women with eclampsia 53

Magnesium sulfate

$52(98.1 \%)$

Other anticonvulsant

$8(15.1 \%)$

Any anticonvulsant

$53(100 \%)$

Cases with SMO

$24(50.9 \%)$

Mortality

$4(7.5 \%)$

Prevention of cesarean-related infection

Target population: women undergoing cesarean

1442

Prophylactic antibiotic during cesarean

$1409(97.6 \%)$

Treatment for sepsis

Target population: women with sepsis

38

Parenteral therapeutic antibiotics

$18(47.4 \%)$

Cases with SMO

$6(15.8 \%)$

Mortality

$2(5.3 \%)$

Ruptured uterus

Target population: women with ruptured uterus $\quad 15$

Laparotomy after $3 \mathrm{~h}$ of hospital stay

$2(13.3 \%)$

Cases with SMO

$12(80.0 \%)$

Mortality

$1(6.7 \%)$

cases per 1000 live births $(M N M R=M N M / L B)$. Similarly to the SMOR, this indicator gives an estimation of the amount of care and resources that would be needed in an area or facility [10]

'Mortality Index (MI): the number of maternal deaths divided by the number of women with life-threatening conditions expressed as a percentage (MI $=\mathrm{MD} /$ $M N M+M D)$. The higher the index the more women with life-threatening conditions die (low quality of care), whereas the lower the index the fewer the women with life-threatening conditions die (better quality of care) [10]

women with sepsis received parenteral treatment with antibiotics. The high patient load at the facility might have a negative impact on quality of care.

Abbreviations: $P P H$ postpartum hemorrhage, SMO severe maternal outcome

The low number of women with SMO admitted into ICU is similar to what other authors in low resource settings found $[25,26]$. It is easy to under-estimate severe morbidity in the absence of sophisticated laboratory diagnostics and shortage of nurse-midwives and clinicians to identify clinical signs of deteriorating patients 
[12, 13]. In sub-Saharan African countries, studies have shown maternal morbidity and mortality can be significantly reduced by improving maternal health care when health workers themselves use audit to identify and analyze deficiencies and apply the findings to improve their obstetric care practices [3, 27]. However, our setting is more focused on treating conditions instead of looking further on how to avoid these in the future. This type of audit will be initiated at Ruhengeri hospital as it is paramount to follow-up actions and maternal health outcomes after an audit [28].

Our study is the first study to be conducted in a rural setting in Rwanda to assess SMO using the new WHO MNM criteria. The advantage of this approach is its standardized methodology, which may allow for a comparison of health facilities and systems. Using this approach led to the integration of regular assessment of the quality of maternal health care in the hospital. In terms of limitations, the lack of follow up after discharge may lead to under reporting of actual MNM and maternal deaths. In addition, the quality of medical records was sometimes poor. We could not apply all WHO criteria due to limited resources at our facility. Some women had severe complications, which did not fulfill any clinical criteria, while laboratory criteria could not be tested for an important part. This may have caused additional under estimation of MNM. Autopsies were not performed and the underlying causes of death were only based on clinical records. Future longitudinal studies should be conducted to assess maternal morbidity and mortality using the $\mathrm{WHO}$ approach nationwide. Interviewing women with MNM may help to elucidate barriers to receiving hospital care.

\section{Conclusions}

In conclusions, MNM is common at district level in Rwanda. Our study highlights some shortfalls in clinical practice and the referral system, improvements of which could lead to further reductions in maternal mortality and morbidity. We recommend intergrated continous quality of care interventions by use of audit at all levels including primary care.

\section{Abbreviations}

Cl: Confidence intervals; ICU: Intensive care unit; MI: Mortality index; MNM: Maternal Near Miss; MNMR: Maternal near miss mortality ratio; PLTC: Potentially life-threatening conditions; SMO: Severe Maternal Outcome; SMOR: Severe Maternal Outcome Ratio; WHO: World Health Organization

\section{Acknowledgments}

The authors thank administration and staff of Ruhengeri hospital; special gratitude goes out to nurse Desire Dusegimana and Dr Rogers Musafiri for their participation in the process of data collection. We are grateful to all women and newborns who participated in this study.

\section{Funding}

No funding received for this study.

\section{Availability of data and materials}

All the necessary data and materials are within this manuscript. In case any more data or materials are needed, they are readily are available on request from the corresponding author according to the Rwanda Ministry of Health guidelines.

\section{Authors' contributions}

RK designed the study protocol, supervised data collection, analyzed and interpreted data, manuscript writing. SR, TvdA, JvR contributed significantly to study design, data analysis, interpretation and manuscript writing. All authors read and approved the final manuscript.

\section{Competing interests}

The authors declare that they have no competing interests.

\section{Consent for publication}

Consent to publish this manuscript from the participants was deemed not applicable since the manuscript does not contain any individual person data.

\section{Ethics approval and consent to participate}

Ethical clearance was obtained from the national ethical committee ( $N^{\circ} 582$ ) RNEC/2013). All data were obtained from medical records and permission to conduct this study was obtained from the medical director. The participants were informed about the study and verbal consent was taken. Written consent was deemed not necessary, since this study was merely an evaluation of clinical care, which should be routine practice in all hospitals. The national ethical committee therefore waived written consent

\section{Author details}

'Department of Obstetrics and Gynecology, Ruhengeri Hospital, Musanze, Rwanda. ${ }^{2}$ Athena Institute, VU University, Amsterdam, The Netherlands. ${ }^{3}$ Department of Obstetrics and Gynecology, University of Rwanda, Kigali, Rwanda. ${ }^{4}$ Department of Obstetrics, Leiden University Medical Centre, Leiden, The Netherlands.

Received: 7 January 2016 Accepted: 18 October 2016

Published online: 21 October 2016

\section{References}

1. Say L, Chou D, Gemmill A, Tuncalp O, Moller AB, Daniels J, et al. Global causes of maternal death: a WHO systematic analysis. Lancet Glob Health. 2014;2(6):e323-33.

2. Hogan MC, Foreman K, Naghavi M, Ahn SY, Wang M, Makela SM, et al. Maternal mortality for 181 countries, 1980-2008: a systematic analysis of progress towards Millennium Development Goal 5. Lancet. 2010;375(9726): 1609-23.

3. van den Akker T, van Rhenen J, Mwagomba B, Lommerse K, Vinkhumbo S, van Roosmalen J. Reduction of severe acute maternal morbidity and maternal mortality in Thyolo District, Malawi: the impact of obstetric audit. PLoS One. 2011:6(6):e20776.

4. Say L, Pattinson RC, Gulmezoglu AM. WHO systematic review of maternal morbidity and mortality: the prevalence of severe acute maternal morbidity (near miss). Reprod Health. 2004;1:3.

5. Tuncalp O, Hindin MJ, Souza JP, Chou D, Say L. The prevalence of maternal near miss: a systematic review. BJOG. 2012:119:653-61.

6. Maternal Health Division. Maternal near miss review: operational guidelines. Ministry of Health \& Family Welfare. New Delhi: Government of India; 2014.

7. Souza JP, Cecatti JG, Haddad SM, Parpinelli MA, Costa ML, Katz L, on behalf of the Brazilian Network for Surveillance of Severe Maternal Morbidity Group, et al. The WHO maternal near-miss approach and the maternal severity index model (MSI): tools for assessing the management of severe maternal morbidity. PLoS One. 2012;7(8):e44129.

8. Tuncalp O, Hindin MJ, Adu-Bonsaffoh K, Adanu RM. Assessment of maternal near-miss and quality of care in a hospital-based study in Accra, Ghana. Int Gynaecol Obstet. 2013;123(1):58-63.

9. Say L, Souza JP, Pattinson RC. Maternal near miss-towards a standard tool for monitoring quality of maternal health care. Best Pract Res Clin Obstet Gynaecol. 2009:23(3):287-96.

10. World Health Organization. Evaluating the quality of care for severe pregnancy complications: the WHO near-miss approach for maternal health. Geneva: WHO; 2011. 
11. Ali AA, Khojali A, Okud A, Adam GK, Adam I. Maternal near-miss in a rural hospital in Sudan. BMC Pregnancy Childbirth. 2011;11:48.

12. van den Akker T, Beltman J, Leyten J, Mwagomba B, Meguid T, Stekelenburg J, van Roosmalen J. The WHO maternal near miss approach: consequences at Malawian District level. PLoS One. 2013;8(1):e54805.

13. Nelissen E, Mduma E, Broerse J, Ersdal H, Evjen-Olsen B, van Roosmalen J, et al. Applicability of the WHO maternal near miss criteria in a low-resource setting. PLoS One. 2013;8(4):e61248.

14. Rulisa S, Umuziranenge I, Small M, van Roosmalen J. Maternal near miss and mortality in a tertiary care hospital in Rwanda. BMC Pregnancy Childbirth. 2015;15:203.

15. National Institute of Statistics of Rwanda, Ministry of Health, and ICF International. Rwanda demographic and health survey 2005. 2006. Available at: http://www.statistics.gov.rw/publications/rwandademographic-andhealth-survey-report-dhs-2005.

16. National Institute of Statistics of Rwanda. Rwanda Demographic and health survey 2014-15. Calverton: Ministry of Health; 2014.

17. Rusa L, Ngirabega JD, Janssen W, Van Bastelaere S, Porignon D, Vandenbulcke W. Performance-based financing for better quality of services in Rwandan health centres: 3-year experience. Trop Med Int Health. 2009; 14(7):830-7.

18. Binagwaho A, Kyamanywa P, Farmer P, Nuthulganti T, Umubyeyi B, Nyemazi $J$, et al. The human resources for health program in Rwanda-a new partnership. N Engl J Med. 2013;369(21):2054-9.

19. Filippi V, Ronsmans C, Gohou V, Goufodji S, Lardi M, Sahel A, et al. Maternity wards or emergency obstetric rooms? Incidence of near-miss events in African hospitals. Acta Obstet Gynecol Scand. 2005;84(1):11-6.

20. David E, Machungo F, Zanconato G, Cavaliere E, Fiosse S, Sululu C, et al. Maternal near miss and maternal deaths in Mozambique: a cross-sectional, region-wide study of 635 consecutive cases assisted in health facilities of Maputo province. BMC Pregnancy Childbirth. 2014;14:401.

21. Pearson L, Shoo R. Availability and use of emergency obstetric services: Kenya, Rwanda, Southern Sudan, and Uganda. Int J Gynecol Obstet. 2005; 88(2):208-15.

22. Mivumbi VN, Little SE, Rulisa S, Greenberg JA. Prophylactic ampicillin versus cefazolin for the prevention of post-cesarean infectious morbidity in Rwanda. Int J Gynaecol Obstet. 2014;124(3):244-7.

23. Rijken MJ, Meguid T, van den Akker T, van Roosmalen J, Stekelenburg J, Dutch Working Party for International Safe Motherhood \& Reproductive Health. Global surgery and the dilemma for obstetricians. Lancet. 2015; 386(10007):1941-2

24. Thaddeus S, Maine D. Too far to walk: maternal mortality in context. Soc Sci Med. 1994;38(8):1091-110.

25. Adisasmita A, Deviany PE, Nandiaty F, Stanton C, Ronsmans C. Obstetric near miss and deaths in public and private hospitals in Indonesia. BMC Pregnancy Childbirth. 2008:8:10

26. Oladapo OT, Sule-Odu AO, Olatunji AO, Daniel OJ. "Near-miss" obstetric events and maternal deaths in Sagamu, Nigeria: a retrospective study. Reprod Health. 2005;2:9.

27. Nyamtema AS, de Jong A, Urassa DP, van Roosmalen J. Using audit to enhance quality of maternity care in resource limited countries: lessons learnt from rural Tanzania. BMC Pregnancy Childbirth. 2011;11:94.

28. Borchert M, Goufodji S, Alihonou E, Delvaux T, Saizonou J, Kanhonou L, et al. Can hospital audit teams identify case management problems, analyse their causes, identify and implement improvements? A cross-sectional process evaluation of obstetric near-miss case reviews in Benin. BMC Pregnancy Childbirth. 2012;12:109.

\section{Submit your next manuscript to BioMed Central and we will help you at every step:}

- We accept pre-submission inquiries

- Our selector tool helps you to find the most relevant journal

- We provide round the clock customer support

- Convenient online submission

- Thorough peer review

- Inclusion in PubMed and all major indexing services

- Maximum visibility for your research

Submit your manuscript at www.biomedcentral.com/submit
Biomed Central 